\title{
Biofeedback Enhanced Lifestyle Intervention: Exploring the Experience of Participants in a Novel Intervention for Disinhibited Eating and Obesity
}

\author{
Tracey Ledoux¹, Martina R. Gallagher ${ }^{2}$, Mario Ciampolini' ${ }^{3}$, McClain Sampson 4 \\ ${ }^{1}$ Department of Health and Human Performance, University of Houston, Houston, USA \\ ${ }^{2}$ Department of Nursing Systems, School of Nursing, University of Texas Health Science Center, Houston, USA \\ ${ }^{3}$ Department of Pediatrics, University of Firenze, Firenze, Italy \\ ${ }^{4}$ Graduate College of Social Work, University of Houston, Houston, USA \\ Email: taledoux@uh.edu, martina.r.gallagher@uth.tmc.edu, mlciampolini@fastwebnet.it, \\ mmsampso@central.uh.edu
}

Received 23 August 2014; revised 24 September 2014; accepted 13 October 2014

Copyright (C) 2014 by authors and Scientific Research Publishing Inc.

This work is licensed under the Creative Commons Attribution International License (CC BY).

http://creativecommons.org/licenses/by/4.0/

(c) (7) Open Access

\begin{abstract}
Obesity increases risks for heart disease, diabetes, and some cancers. Disinhibited Eating (DE) is an inconsistent ability to control overeating in the absence of hunger and is related to obesity and failed weight loss attempts. However, there are no effective interventions for simultaneously treating DE and obesity, so the Biofeedback Enhanced Lifestyle Intervention (BELI) was developed. BELI included novel techniques and some that could be considered burdensome and uncomfortable. Evidence of acceptability and feasibility of BELI should be established before resources are devoted to an efficacy study. This study aimed to evaluate the acceptability and feasibility of BELI. Overweight/obese $(0 \mathrm{~W} / \mathrm{Ob})$ women with a tendency toward DE were recruited. BELI consisted of five counseling sessions, hunger biofeedback, child role modeling, and self-monitoring. Focus group data, process evaluation data, a satisfaction survey, and objective measures of weight and eating behaviors were collected. In exit focus groups participants reported BELI facilitated positive changes. Process evaluation data showed modest attrition $(20 \%)$, good compliance, and feasibility of delivery. $100 \%$ of BELI completers reported high satisfaction. There were trends in improvements in weight status, eating behaviors, mood, and stress. Implications of this study are to conduct a pilot study of BELI to establish efficacy.
\end{abstract}

\section{Keywords}

Disinhibited Eating, Feasibility, Obesity, Hunger Biofeedback

How to cite this paper: Ledoux, T., Gallagher, M.R., Ciampolini, M. and Sampson, M. (2014) Biofeedback Enhanced Lifestyle Intervention: Exploring the Experience of Participants in a Novel Intervention for Disinhibited Eating and Obesity. Open Journal of Preventive Medicine, 4, 779-788. http://dx.doi.org/10.4236/ojpm.2014.410088 


\section{Introduction}

Obesity dramatically increases risks for diabetes, heart disease, and some cancers [1]-[3]. Effective obesity treatments are needed to prevent a myriad of chronic conditions [4] [5]. Half of childbearing age women are obese [6] [7]. There has been some suggestion that there are multiple subtypes of obesity requiring different treatment approaches [4] [5]. For some individuals eating in the absence of hunger and loss of control eating contribute to obesity and standard evidence-based weight loss approaches exacerbate these eating problems [8]. Disinhibited Eating (DE) is the inconsistent ability to resist the urge to overeat in the absence of hunger [9], negative emotions and external stimuli trigger DE [8]-[11]. DE is related to obesity, chronic dieting, and weight cycling [8]-[13]. There are a number of interventions that have reduced the tendency toward DE, but none have simultaneously reduced overweight or obese status [14] [15]. Given that many who struggle with DE have issues with obesity and weight cycling, healthy weight stability should be a goal of DE interventions.

Interventions that reduce DE promote internal dietary control strategies, discourage rigid dietary restraint, and address emotional and external overeating [14]-[17]. Internal dietary control strategies refer to the use of hunger/ satiety sensations to determine what, when, and how much to eat [14] [15] [18]-[20]. Programs that promote internal dietary control strategies rest on an assumption that most can accurately identify physical hunger. However, research shows many overweight and obese (OW/Ob) individuals confuse physical hunger with other nonmetabolic urges to eat (e.g., emotions, cravings) [21]. DE interventions need to include tools to teach individuals how to recognize physical hunger and practice internal dietary control.

The hunger biofeedback technique was developed by Mario Ciampolini, MD based on Glucostatic Theory, which posits that Blood Glucose (BG) levels and physical hunger fluctuate together [22]-[24]. For this technique (also known as "hunger recognition" by Dr. Ciampolini), participants are given a portable BG self-monitoring device and instructed to eat only when physical hunger is confirmed (BG in the target range of $60-85 \mathrm{mg} / \mathrm{dl}$ ). Dr. Ciampolini showed Italian adults of varying weight statuses with gastrointestinal conditions learned to accurately recognize physical hunger [23] [25] [26]. Dr. Ciampolini found the hunger biofeedback technique resulted in weight loss and improved insulin resistance. The strengths of hunger biofeedback are that it objectively teaches people to identify physical hunger sensations and it is a short-term technique. Dr. Ciamoplini's participants learned to recognize physical hunger by practicing hunger biofeedback $\leq 14$ days. Potential barriers to widespread use of hunger biofeedback is it requires BG self-monitoring which can be experienced as uncomfortable, embarrassing, and inconvenient. The acceptability of this approach within a DE intervention needs to be determined.

Vicarious learning is a powerful tool for learning new behaviors. Observing those who determine what, when, and how much to eat based on internal hunger/satiety cues may help disinhibited eaters learn internal dietary control. Infants are born with an innate ability to eat in response to internal cues and tend to retain this ability until at least age four when some children begin to show signs of DE [27] [28]. Clinicians often refer to toddler age children as models of internally regulated eating [16]; however, this intervention strategy has never been tested.

BELI (Biofeedback Enhanced Lifestyle Intervention) was developed with the goal of reducing DE and weight among OW/Ob women. It is based on research and behavior change theory. It emphasizes strategies shown to reduce DE like emphasizing internal dietary control, discouraging rigid dietary restraint, and addressing emotional and external overeating. BELI also includes unconventional techniques like hunger biofeedback and child role modeling, both of which have questionable acceptability. While the use of novel techniques is essential in addressing behaviors that perpetuate the obesity problem, the risk is that these strategies will not be acceptable or feasible for the target population. Research resources are growing increasingly scarce, and resource scarcity often leads to risk aversion. Now more than ever, it is important to conduct small-scale studies to determine acceptability and feasibility of interventions in an effort to conserve resources for larger randomized controlled pilot studies [29]. This approach reduces risk without compromising innovation.

The aim of this study was to determine acceptability and feasibility of BELI and to identify aspects of BELI requiring revision to accommodate members of the priority population. Specifically, qualitative data (focus groups), quantitative (self-report surveys), and observation (process evaluation) data were collected to achieve this aim. Changes in disinhibited eating, body mass index, negative mood, stress, and internally controlled eating behaviors were also explored. 


\section{Methods}

\subsection{Sample}

Inclusion criteria were: Body Mass Index (BMI) $\geq 25, \geq 18$ years, custodian of a child between one and three years of age, English language literacy, sedentary lifestyle ( $<150$ minutes of moderate to vigorous physical activity per week), and history of DE. Exclusion criteria were pregnant, lactating and/or glucose intolerance.

\subsection{Recruitment and Screening}

Participants were recruited in 2012 through community advertisements. Interested women underwent telephone screening, which included the Revised Restraint Scale (RRS) [30] to determine tendency toward DE (score of $\geq 15$ ) [30]. The primary aim of the study was to determine feasibility and acceptability, so no minimum sample size calculations were conducted.

\subsection{Procedures}

This feasibility study was approved by the committee for the protection of human subjects. Participants provided documentation of consent before any data was collected or intervention procedures conducted. Exploratory outcomes were assessed at baseline (T1) and immediate post (T2). Process evaluation measures were tracked throughout the study and focus groups and satisfaction surveys were conducted at $\mathrm{T} 2$.

\subsection{Intervention}

BELI included five counseling sessions on the role of hunger/satiety and energy balance, using meal composition and size to manipulate hunger, coping with emotions, coping with external eating, and planning for maintenance. Each counseling session included a progress update, topic discussion, and goal setting in 45 - 60 minutes. Between sessions participants practiced hunger biofeedback [23]. In session one, participants were instructed to suspend eating episodes until physical hunger was perceived and confirmed with portable BG monitor (BG levels 60 - $85 \mathrm{mg} / \mathrm{dl}$ ). If physically hungry, they were to be mindful of the sensations, log the experience, and eat a sensible meal/snack. If BG levels were $>85 \mathrm{mg} / \mathrm{dl}$ they were encouraged to 1) abstain from eating, 2) identify the trigger, 3) implement a coping strategy, and 4) log the experience. Participants were provided with necessary supplies and instructions in session one. Continued need for hunger biofeedback was evaluated weekly. Participants maintained logs of estimated BG, actual BG, hunger sensations or trigger, and situation each time they thought they were hungry. In all sessions, facilitators discussed how the participants' toddler age children demonstrated internal eating.

\subsection{Staff}

The PI, who is a licensed psychologist and registered dietitian, and a nutrition graduate student conducted all counseling sessions. The graduate student received weekly supervision and 33.5 hours of training on the curriculum, the conduct of ethical human subject research, and basic counseling techniques. A Research Assistant (RA) with training in phlebotomy, anthropometry, and the study assessment protocol (10 hours of training) conducted $\mathrm{T} 1$ and $\mathrm{T} 2$ assessments.

\subsection{Focus Groups}

Participants $(n=8)$ shared their personal experiences in BELI through exit focus groups. A moderately-structured open-ended interview script was created: What was your experience 1) in this program, 2) in the counseling sessions, 3) with the hunger biofeedback technique, and 4) completing the food and hunger log? Also, to what extent were your toddler age children role models for you in this program? Two interviewers who had advanced graduate training in conducting focus groups facilitated the focus groups (one moderator and one took behavioral observation notes). Interviewers prompted participants for thoughts, feelings, and behaviors related to their experience with each component of BELI. They were encouraged to be honest and provide suggestions for future BELI iterations. Focus groups were audio recorded and transcribed for analysis. The focus group facilitators had not been previously involved with data collection or intervention. The focus groups took no more than 2 hours. 


\subsection{Process Evaluation}

Participation rates and reasons for early withdrawal were tracked. Research staff made every effort through email, phone, and text to provide participants with opportunities to explain their choices for withdrawing or staying in the program and these responses were logged. In order to understand participant experience in BELI it was important to quantify the amount of contact and exposure participants had with elements of BELI including sessions with counselors and engagement in homework assignments. The number and length of sessions attended and frequency of completed or semi-completed homework assignments (hunger biofeedback and selfmonitoring) were logged by counselors. Fidelity referred to the proportion of the curriculum components and sessions that were delivered by counselors. Fidelity of facilitator counseling was also determined with review of audiorecordings of each session.

\subsection{Measures}

Demographics. Demographic data were determined via self-report questionnaire at T1.

Satisfaction Survey. At T2 participants completed a survey to determine the extent to which participants enjoyed, learned from, and valued BELI overall and each component including the counseling sessions, hunger biofeedback, food/hunger diary.

BMI. While wearing light clothing at T1 and T2, height (inches) and weight (pounds) were measured twice and averaged to calculate BMI (wt $(\mathrm{kg}) / \mathrm{ht}\left(\mathrm{m}^{2}\right)$ ).

Fasting BG. At T1 and T2, after an eight hour fast, a small capillary blood sample ( $<0.25 \mathrm{~mL})$ was collected using a lancet from a fingertip and serum blood glucose was determined using a Freestyle Lite blood glucose monitor (Abbott, Alameda, CA).

Ability to Recognize Hunger. Ability to recognize physical hunger was operationally defined as the difference between measured BG level $(\mathrm{mg} / \mathrm{dl})$ and the self-reported value $(\mathrm{mg} / \mathrm{dl})$ provided in response to the following question [23]: "Most people report feeling hungry enough to eat when their BG levels are between 60 and $85 \mathrm{mg} / \mathrm{dl}$. Two hours after a meal, BG levels may be as high as $140 \mathrm{mg} / \mathrm{dl}$. Based on your current level of hunger, what do you think your current BG reading is in $\mathrm{mg} / \mathrm{dl}$ ?”

Energy Intake. At T1 and counseling session five, participants were given a 3-day food diary and instructions for completing it on two weekdays and one weekend day because consumption on weekend days is substantially different from weekdays and three non-consecutive days to overcome day-to-day variability of diet. Participants returned baseline food diaries at the first counseling session and post-intervention food diaries at T2. Food diary entries were analyzed with the USDA nutrient analysis program (http://www.nal.usda.gov/fnic/foodcomp/search), and average daily total energy intake was determined.

Internal Dietary Control. At T1 and T2, extent to which one uses internal dietary control strategies was measured using the Intuitive Eating Scale (IES) [31], which is a 21-item validated [31] self-report scale with very good internal consistency (Cronbach's alpha $=0.89$, [31]) and test-retest reliability $(r=0.90$, [31]). Subscales include unconditional permission to eat, eating for physical hunger not emotion, and reliance on hunger and satiety to determine eating episodes.

Disturbed Eating. The Dutch Eating Behavior Questionnaire [32] is a 33-item measure of rigid restraint and disinhibited eating (i.e., external and emotional overeating). The DEBQ has been widely used and has very good internal consistency and validity among normal, eating disordered, and dieting women [32] [33]. Paticipants completed the DEBQ at T1 and T2.

Mood. The Mood Rating Scale (MRS) [34] is a 17-item measure of current state mood status. It has good internal consistency for positive emotions $(0.86$ - 0.88) and negative emotion $(0.74-0.76)$. Participants completed the MRS at T1 and T2.

Stress. The Perceived Stress Scale (PSS) [35] is a 10-item measure of perceived personal stress with very good internal reliability and validity [35]. Participants completed the PSS at T1 and T2.

\subsection{Data Analysis Methods}

Qualitative description was used to assess the subjective experience of participants in BELI from a naturalistic theoretical orientation as described by [36] [37]. Audiorecordings of focus groups were analyzed using qualitative content analysis [36] [37]. Audiorecordings rather than transcripts were used so that qualities of voice and 
tone could be captured. Two trained coders used a multi-pass method to independently code transcripts. On the first pass, coders listened to audiorecordings of focus groups straight through without stopping to immerse themselves in the data. In a second pass, coders reviewed recordings while noting key points within each interview guide question. Instructions for this pass were to stop the recordings as often as needed to identify key points that are strongly related to the interview question or repeated by multiple participants. Coders then clustered the key points into themes within each interview question response. The independent coders then consolidated their final list of themes into one final list. The lead author (TL) was available to settle disagreements. Independently coders reviewed transcripts to confirm the final list of themes and to identify participant quotes that exemplified each theme.

SPSS 20 (Armonk, NY) was used to conduct quantitative analyses. Means, standard deviations, frequencies, and correlation analyses determined violations in assumptions and described sample characteristics. A significance value of 0.10 was used in this pilot study. To determine changes in outcomes, paired t-tests were used to compare pre and post values. Given the small sample size, and non-normal distributions, the non-parametric test equivalent Wilcoxin Rank was conducted for each outcome. Because there were no differences in results between the two tests and effect sizes can be calculated using t-values, paired t-test results are reported here. Frequency counts and ratios were tabulated to determine attrition, dose, and fidelity. Means and standard deviations of scores of items on the Satisfaction Survey were calculated.

\section{Results}

\subsection{Sample Characteristics}

Ten women were recruited for this study. Average BMI at baseline was 35.8 (7.5 SD), and age was 31 (7.8 SD). Four women (40\%) were non-Hispanic white, two (20\%) were non-Hispanic black, two (20\%) were Hispanic white, and two (20\%) were Hispanic black. Eight women (80\%) were married and two (20\%) were in an unmarried relationship. Four women (40\%) had more than a college education, four (40\%) had some college education, and two $(20 \%)$ had a high school degree. Half the participants $(n=5)$ had household incomes $\geq \$ 50 \mathrm{~K}$, three (30\%) had household incomes between $\$ 20$ and $\$ 50 \mathrm{~K}$, and two (20\%) had household incomes $<\$ 20 \mathrm{~K}$. Participants had 1 - 3 children.

\subsection{Qualitative Data: Focus Groups}

Two focus groups were conducted with three and four participants. One in-depth interview was conducted due to schedule conflicts with focus group times.

Overall Experience of the Program. Participants reported learning how to use internal sensations to inform eating. One participant said, “...it was a really good experience getting to know your body and hunger cues and triggers and things like that within yourself.” For women who had a long history of chronic dieting with failed weight loss attempts, the idea that weight management could be achieved by relying on internal sensations rather than external diet rules was novel, intriguing, and a bit scary. During the course of the intervention participants became quite aware of the rigid diet beliefs they had been using to inform their eating. Some of the more common myths had to do with timing of meals (e.g., avoid eating after $7 \mathrm{p}$ and always eat breakfast), content of meals (e.g., avoid fat and sugar), and context of meals (e.g., never overeat in front of people). It was difficult to let these firmly held beliefs go. One participant said, "I always felt guilty for eating a hamburger... my whole life had been 'lite' this and 'lite' that and salads... so that was nice to take the stress off." While this acknowledgement was liberating for the women, it was also intimidating and overwhelming as they expressed concerns about trusting their bodies.

Experience of the Counseling Sessions. Participants enjoyed the emotional support and accountability they received in the counseling sessions. One participant said of them, "I looked forward to them (the counseling sessions) every 2 - 4 weeks because I had somebody to talk to.” Weight and the approach these women took to managing their weight was a highly stressful and shameful topic, so having a confidante to talk to about these issues was a relief. Another participant claimed, "It was nice to have someone to talk to that you don't about anything else. Something in your life that was really stressful and you didn't know how to overcome-you would be able to come here. That helped-the assistance, those nice words."

The counseling sessions fostered self-awareness and discovery of personal patterns and motives. One partici- 
pant said, “I walked out of my counseling sessions feeling things I didn’t realize were there. I learned more how to cope with stress." Several participants came out of BELI with a greater understanding of the connection between their eating habits and emotions. Another participant claimed, "I never realized how my emotions are tied to my eating - that was really eye opening." It took the participants several sessions to come to this realization, so it was not surprising that participants indicated a desire for more counseling sessions be added to BELI so that emotional aspects of eating could be explored in depth. Participants felt like they were just starting to make this connection by the end of BELI. One participant said, "Because of the counseling sessions I am on the track to understanding why I am eating now and I just need to put in the self-control part of it."

Hunger Biofeedback. Participants found hunger biofeedback to be acceptable and instrumental in learning to recognize physical hunger. One participant reported, "I thought it was really helpful to question whether I was really hungry or not because of course I'm going to think I'm hungry any time I think about food. It was really helpful to get a second opinion (blood glucose monitor) on whether I need to put food in my body or not." The participants denied having any difficulties conducting hunger biofeedback: "The pricking and jotting (food diary) wasn't hard." Another reported a similar sentiment, "Not difficult at all. It was very helpful." Participants seemed to depend on the blood glucose monitor readings to determine when they were hungry early in the intervention. One participant said, "I learned that I get really bad headaches and grumpy if my number gets in the 60's.” As BELI progressed they became more skilled at recognizing hunger. Another said of predicting her own blood glucose levels, “...I would get close because I learned what a feeling meant.” Others said, "I feel hungry, why is it saying I'm not? After the weeks went on, my mind was agreeing and my body was agreeing with what the glucose monitor was showing."

Experience of the Hunger/Food Logs. Participants found the logs helpful in learning patterns. For example, one woman said, "It has been very beneficial, especially when I have stressful days. I'll keep it (hunger/food diary) up all day on my computer so I don't catch myself in old eating patterns-eating just to eat.” Most found the logs motivated them to adhere to BELI. One participant said, "It's the accountability. Knowing that I had to write it down and someone was going to look at it made me more accountable for my choices.” However, over time, participants found it burdensome. One participant said, "I got tired of having to write down and forgetting what I had.”

Children as Examples. Participants noticed how their child's eating patterns were influenced by internal cues. One woman reported:

I was more aware of when my daughter would say she is full and more aware of how she wouldn't finish her ice cream, so that was really helpful to teach me- just because it's right there in front of you and it's really good and it's something you have been waiting for-you don't have to finish it all if you're not hungry.

Many of the women talked about being more attentive to their children while eating and learning from their example. One woman said, "My youngest—you can give him full access and he's not going to eat all of it—only what he wants. That helped me...” Another woman reported, “They don't know what time it is. If it's lunch time, they know when they are hunger-I paid more attention to that."

\subsection{Self-Report Satisfaction Survey}

On a 10 point Likert scale with 10 indicating "very much" and 1 indicating "not at all”, on average, study completers $(n=8)$ were highly satisfied with the intervention overall $(8.5 / 10)$, the counseling sessions $(9 / 10)$, hunger biofeedback (8.5/10), and self-monitoring (7.8/10). Overall satisfaction scores ranged from 6.46 to 10 indicating moderate to high satisfaction. Satisfaction survey scores indicated participants enjoyed (8.1/10), valued (8.8/10), and learned from the program (8.8/10).

\subsection{Observational Data}

Attrition. 20\% of sample dropped out due to loss of childcare and work schedule conflict.

Dose. Seven (88\%) study completers $(\mathrm{n}=8)$ attended all counseling sessions, and one (12\%) completed two. Among study completers $(\mathrm{n}=8)$, the session length ranged from 42.4 to 62 minutes (M 51.35, SD 6.5).

Fidelity. $100 \%$ of the counseling sessions covered $100 \%$ of the curriculum. A review of audiorecordings of counseling sessions indicated high degree of fidelity to the facilitator guide. 


\subsection{Exploratory Outcomes}

Mean weight loss was $2.09 \mathrm{~kg}$ (SD 1.7) (see Table 1). There was a reduction in BMI, restrained eating, disinhibited emotional eating, disinhibited external eating, and energy intake with an increase in ability to recognize hunger from pre to post. Use of internal dietary control, unconditional permission to eat, reliance on hunger/satiety cues to eat, and eating for physical hunger versus emotional needs increased (Table 1).

\section{Discussion}

BELI was well received by participants. Attrition was modest and due to unavoidable barriers common among mothers: lack of child care and changing work schedules. BELI was delivered with fidelity without exceeding an acceptable session length (45 - 60 minutes). Participants reported high levels of enjoyment, perceived value, satisfaction, and learning from each BELI component. Participants perceived hunger biofeedback, the counseling sessions, toddler role modeling, and the hunger and food logs as necessary for the learning that occurred.

Participants found the hunger biofeedback technique to be a critical tool in learning to recognize hunger. Biofeedback is a technique often used in therapies based in cognitive behavioral theory used to make unconscious biological processes conscious to inform behavioral choice [38]. In this regard, hunger biofeedback makes the experience of hunger known and this informs eating behavior and food choice. Benefits of hunger biofeedback are it offers an objective standard for participants to compare their subjective experience to and it is brief. Once participants consistently and accurately gauge their hunger levels compared to BG levels, they can begin to discontinue use of BG monitoring. Most participants in Ciampolini's studies learned to recognize physical hunger within 14 days [23] [25] [39]. An unanticipated effect that occurred in this study was that participants became fixated with their BG readings. Participants had trouble trusting themselves to identify their hunger levels without the use of the device even though they repeatedly demonstrated greater accuracy in their ability to predict their BG levels at the time of hunger. In this study, participants were encouraged to use the hunger biofeedback technique for as long as they felt it was necessary. In future iterations of BELI, counselors should remind participants that the technique is a guide to facilitate learning not a permanent aid. In addition, counselors could take a more active role in weaning participants from the device by assigning days or periods of time when participants could practice reading their own hunger levels without the device.

Table 1. Baseline and post BELI measures and paired t-test significance test results $(n=8)$.

\begin{tabular}{|c|c|c|c|c|c|c|}
\hline \multirow[t]{2}{*}{ Measure } & \multicolumn{2}{|c|}{ Baseline } & \multicolumn{2}{|c|}{ Post } & \multirow[t]{2}{*}{ Sig } & \multirow[t]{2}{*}{ Eta Sq+ } \\
\hline & M & SD & M & $\mathrm{SD}$ & & \\
\hline BMI (wt (kg)/ht $\left.\left(\mathrm{m}^{2}\right)\right)$ & 35.5 & 8.3 & 34.7 & 8.3 & $p=0.015$ & 0.59 \\
\hline Hunger recognition (absolute $\mathrm{mg} / \mathrm{dl}$ ) ${ }^{*}$ & 15.5 & 6.1 & 8.8 & 7.4 & $p=0.022$ & 0.55 \\
\hline Energy intake (kcal/d) & 1614 & 210.2 & 1265.1 & 227 & $\mathrm{p}<\mathbf{0 . 0 0 1}$ & 0.94 \\
\hline \multicolumn{7}{|l|}{ Disturbed eating } \\
\hline Restraint (DEBQ) & 6 & 2.8 & 5.5 & 2.7 & $\mathrm{p}=0.562$ & 0.05 \\
\hline Disinhibited emotional overeating (DEBQ) & 6 & 4.4 & 4.6 & 5.4 & $\mathrm{p}=0.282$ & 0.16 \\
\hline Disinhibited external overeating (DEBQ) & 6.3 & 1.6 & 4.6 & 2.2 & $\mathbf{p}=\mathbf{0 . 0 0 7}$ & 0.7 \\
\hline \multicolumn{7}{|l|}{ Internal dietary control strategies } \\
\hline IES Total & 59.3 & 6.5 & 74.4 & 12 & $p=0.028$ & 0.79 \\
\hline Unconditional permission to eat (IES) & 21.75 & 3.3 & 26.6 & 6.4 & $p=0.051$ & 0.44 \\
\hline Eating for physical hunger rather than emotion (IES) & 16.3 & 4.7 & 23.9 & 5.5 & $\mathrm{p}<0.001$ & 0.89 \\
\hline Reliance on hunger/satiety cues to eat (IES) & 21.3 & 2.6 & 23.9 & 2.5 & $\mathrm{p}=0.116$ & 0.31 \\
\hline Perceived stress (PSS) & 19.6 & 7 & 10.7 & 6.6 & $\mathrm{p}=0.103$ & 0.38 \\
\hline Positive mood (MRS) & 38.4 & 5.2 & 42.1 & 8.6 & $\mathrm{p}=0.353$ & 0.12 \\
\hline Negative mood (MRS) & 16 & 7.1 & 13 & 4.4 & $p=0.131$ & 0.3 \\
\hline
\end{tabular}

*Calculated as the difference between estimated blood glucose levels and measured blood glucose levels; +Eta sq refers to effect sizes with $0.01=$ small effect, 0.06 = moderate effect, and 0.14 = larger effect. BELI = Biofeedback Enhanced Lifestyle Intervention; BMI = Body Mass Index; DEBQ = Dutch Eating Behavior Questionnaire; IES = Intuitive Eating Scale; PSS = Perceived Stress Scale; MRS = Mood Rating Scale. 
Toddler role modeling was a completely novel concept but well received by the participants in this study. There are a number of studies that have shown parents are strong role models for children [40], however no known studies have tested the effectiveness of using children as role models for parents. Clinicians refer to young children as examples of individuals who practice internally regulated eating [16]. Animal and human research has shown that meal initiation and termination are driven by hunger/satiety but that as children reach preschool age (3 - 5 years), they begin to learn to associate environmental cues with food [41]. As this occurs, meal initiation and termination become influenced not only by hunger/satiety but also by environmental cues [41]. Social Cognitive Theory suggests observation is an important method of learning [42]. When directed to notice their children's eating behaviors, participants in this study reported learning something about internally regulated eating.

Exploratory outcome results showed a reduction in disinhibited eating (external and emotional overeating) and negative mood from pre to post BELI delivery. However, in focus groups, participants reported they did not think BELI adequately addressed their emotional needs. Early in the intervention, many participants were unaware of the ways emotions influenced their eating behaviors. The food/hunger diaries helped them gain insights into the connection between their emotions and eating behaviors. Unfortunately, by the time this realization was made, there were few remaining sessions for discussions about how to cope with negative emotions without food. Future iterations of BELI should include a greater emphasis on emotional coping, possibly with additional sessions.

Participants reported finding the intervention to be "eye opening" and helped them relax their strict diet mentality. Women appeared to lose weight without increasing restraint and granted themselves greater unconditional permission to eat when, what, and how much they wanted. No studies have shown weight loss can be achieved without increasing restraint. This may have long term implications for weight loss maintenance because rigid restraint has been associated with weight cycling, failed weight loss attempts, and DE.

Limitations of this study include very small sample size and lack of control group; however the goal of the study was to establish acceptability of BELI before resources are used to conduct a larger scale pilot study of weight and eating behavior outcomes of BELI. The participants enjoyed BELI, found the information and tasks valuable, and complied with the instructions they were given for keeping the hunger/food diaries and hunger biofeedback. Future research should expand BELI to include more support in weaning off of hunger biofeedback and discussion about emotional coping. The revised version of BELI should then be pilot tested against a control group to determine preliminary effects for planning a fully powered randomized controlled trial. Other limitations include the fact that much of the data came from self-report. Self-report data may be subject to bias and human error of judgment or memory.

\section{Conclusion}

This study demonstrated how a novel intervention with questionable acceptability can be tested for acceptability and feasibility. This approach reserves limited resources for conducting efficacy and later effectiveness trials for interventions or programs that have established public acceptability and feasibility of delivery. BELI proved to be acceptable among the priority population and feasible to deliver. Results of this feasibility study justify the need for a larger study of the effects of BELI against a control group with a larger fully powered sample with long-term follow-up.

\section{References}

[1] Hussain, A., Claussen, B., Ramachandran, A. and Williams, R. (2007) Prevention of Type 2 Diabetes: A Review. Diabetes Research and Clinical Practice, 76, 317-326. http://dx.doi.org/10.1016/j.diabres.2006.09.020

[2] Danaei, G., Ding, E.L., Mozaffarian, D., Taylor, B., Rehm, J., Murray, C.J. and Ezzati, M. (2009) The Preventable Causes of Death in the United States: Comparative Risk Assessment of Dietary, Lifestyle, and Metabolic Risk Factors. PLOS Medicine, 6, e1000058. http://dx.doi.org/10.1371/journal.pmed.1000058

[3] Roberts, D.L., Dive, C. and Renehan, A.G. (2010) Biological Mechanisms Linking Obesity and Cancer Risk: New Perspectives. Annual Review of Medicine, 61, 301-316. http://dx.doi.org/10.1146/annurev.med.080708.082713

[4] Davis, C. (2009) Psychobiological Traits in the Risk Profile for Overeating and Weight Gain. International Journal of Obesity (Lond), 33, S49-S53. http://dx.doi.org/10.1038/ijo.2009.72

[5] Davis, C., Curtis, C., Levitan, R.D., Carter, J.C., Kaplan, A.S. and Kennedy, J.L. (2011) Evidence That "Food Addic- 
tion” Is a Valid Phenotype of Obesity. Appetite, 57, 711-717. http://dx.doi.org/10.1016/j.appet.2011.08.017

[6] Flegal, K.M., Carroll, M.D., Kit, B.K. and Ogden, C.L. (2012) Prevalence of Obesity and Trends in the Distribution of Body Mass Index among US Adults, 1999-2010. The Journal of the American Medical Association, 307, 491-497. http://dx.doi.org/10.1001/jama.2012.39

[7] Vahratian, A. (2009) Prevalence of Overweight and Obesity among Women of Childbearing Age: Results from the 2002 National Survey of Family Growth. Maternal and Child Health Journal, 13, 268-273. http://dx.doi.org/10.1007/s10995-008-0340-6

[8] Niemeier, H.M., Phelan, S., Fava, J.L. and Wing, R.R. (2007) Internal Disinhibition Predicts Weight Regain Following Weight Loss and Weight Loss Maintenance. Obesity, 15, 2485-2494. http://dx.doi.org/10.1038/oby.2007.295

[9] Bryant, E.J., King, N.A. and Blundell, J.E. (2008) Disinhibition: Its Effects on Appetite and Weight Regulation. An Official Journal of the International Association for the Study of Obesity, 9, 409-419. http://dx.doi.org/10.1111/j.1467-789X.2007.00426.x

[10] Butryn, M.L., Thomas, J.G. and Lowe, M.R. (2009) Reductions in Internal Disinhibition during Weight Loss Predict Better Weight Loss Maintenance. Obesity, 17, 1101-1103. http://dx.doi.org/10.1038/oby.2008.646

[11] French, S.A., Epstein, L.H., Jeffery, R.W., Blundell, J.E. and Wardle, J. (2012) Eating Behavior Dimensions. Associations with Energy Intake and Body Weight: A Review. Appetite, 59, 541-549. http://dx.doi.org/10.1016/j.appet.2012.07.001

[12] Wing, R.R. and Phelan, S. (2005) Long-Term Weight Loss Maintenance. The American Journal of Clinical Nutrition, 82, 222S-225S.

[13] McGuire, M.T., Wing, R.R., Klem, M.L., Lang, W. and Hill, J.O. (1999) What Predicts Weight Regain in a Group of Successful Weight Losers? Journal of Consulting and Clinical Psychology, 67, 177-185.

[14] Bacon, L. and Aphramor, L. (2011) Weight Science: Evaluating the Evidence for a Paradigm Shift. Nutrition Journal, 10, 9. http://dx.doi.org/10.1186/1475-2891-10-9

[15] Bacon, L., Stern, J.S., Van Loan, M.D. and Keim, N.L. (2005) Size Acceptance and Intuitive Eating Improve Health for Obese, Female Chronic Dieters. Journal of the American Dietetic Association, 105, 929-936. http://dx.doi.org/10.1016/j.jada.2005.03.011

[16] Tribole, E. and Resch, E. (1995) Intuitive Eating: A Revolutionary Program That Works. Saint Martin’s Paperbacks, New York.

[17] Miller, C.K., Kristeller, J.L., Headings, A., Nagaraja, H. and Miser, W.F. (2012) Comparative Effectiveness of a Mindful Eating Intervention to a Diabetes Self-Management Intervention among Adults with Type 2 Diabetes: A Pilot Study. Journal of the Academy of Nutrition and Dietetics, 112, 1835-1842. http://dx.doi.org/10.1016/j.jand.2012.07.036

[18] Hay, P.P., Bacaltchuk, J., Stefano, S. and Kashyap, P. (2009) Psychological Treatments for Bulimia Nervosa and Binging. Cochrane Database of Systematic Reviews, 4, Article ID: CD000562.

[19] Niemeier, H.M., Leahey, T., Reed, K.P., Brown, R.A. and Wing, R.R. (2012) An Acceptance-Based Behavioral Intervention for Weight Loss: A Pilot Study. Behavior Therapy, 43, 427-435. http://dx.doi.org/10.1016/j.beth.2011.10.005

[20] Forman, E.M., Hoffman, K.L., McGrath, K.B., Herbert, J.D., Brandsma, L.L. and Lowe, M.R. (2007) A Comparison of Acceptance- and Control-Based Strategies for Coping with Food Cravings: An Analog Study. Behaviour Research and Therapy, 45, 2372-2386. http://dx.doi.org/10.1016/j.brat.2007.04.004

[21] Barkeling, B., King, N.A., Näslund, E. and Blundell, J.E. (2007) Characterization of Obese Individuals Who Claim to Detect No Relationship between Their Eating Pattern and Sensations of Hunger or Fullness. International Journal of Obesity, 31, 435-439. http://dx.doi.org/10.1038/sj.ijo.0803449

[22] Campfield, L.A. and Smith, F.J. (2003) Blood Glucose Dynamics and Control of Meal Initiation: A Pattern Detection and Recognition Theory. Physiological Reviews, 83, 25-58.

[23] Ciampolini, M. and Bianchi, R. (2006) Training to Estimate Blood Glucose and to Form Associations with Initial Hunger. Nutrition \& Metabolism, 3, 42. http://dx.doi.org/10.1186/1743-7075-3-42

[24] Siegmund, T., Rad, N.T., Ritterath, C., Siebert, G., Henrich, W. and Buhling, K.J. (2008) Longitudinal Changes in the Continuous Glucose Profile Measured by the CGMS ${ }^{\circledR}$ in Healthy Pregnant Women and Determination of Cut-Off Values. European Journal of Obstetrics and Gynecology and Reproductive Biology, 139, 46-52. http://dx.doi.org/10.1016/j.ejogrb.2007.12.006

[25] Ciampolini, M. and Sifone, M. (2011) Differences in Maintenance of Mean Blood Glucose (BG) and Their Association with Response to “Recognizing Hunger”. International Journal of General Medicine, 4, 403-412. http://dx.doi.org/10.2147/IJGM.S19035

[26] Ciampolini, M., Lovell-Smith, D. and Sifone, M. (2010) Sustained Self-Regulation of Energy Intake. Loss of Weight 
in Overweight Subjects. Maintenance of Weight in Normal-Weight Subjects. Nutrition \& Metabolism, 7, 4. http://dx.doi.org/10.1186/1743-7075-7-4

[27] Ashcroft, J., Semmler, C., Carnell, S., van Jaarsveld, C.H. and Wardle, J. (2008) Continuity and Stability of Eating Behaviour Traits in Children. European Journal of Clinical Nutrition, 62, 985-990. http://dx.doi.org/10.1038/sj.ejcn.1602855

[28] Carnell, S. and Wardle, J. (2009) Appetitive Traits in Children. New Evidence for Associations with Weight and a Common, Obesity-Associated Genetic Variant. Appetite, 53, 260-263. http://dx.doi.org/10.1016/j.appet.2009.07.014

[29] Bowen, D.J., Kreuter, M., Spring, B., Cofta-Woerpel, L., Linnan, L., Weiner, D., Bakken, S., Kaplan, C.P., Squiers, L., Fabrizio, C., et al. (2009) How We Design Feasibility Studies. American Journal of Preventive Medicine, 36, 452-457. http://dx.doi.org/10.1016/j.amepre.2009.02.002

[30] Herman, C.P. and Polivy, J. (1980) Restrained Eating. Saunders, Philadelphia.

[31] Augustus-Horvath, C.L. and Tylka, T.L. (2011) The Acceptance Model of Intuitive Eating: A Comparison of Women in Emerging Adulthood, Early Adulthood, and Middle Adulthood. Journal of Counseling Psychology, 58, 110-125. http://dx.doi.org/10.1037/a0022129

[32] Van Strien, T., Frijters, J.E.R., Bergers, G.P.A. and Defares, P.B. (1986) The Dutch Eating Behavior Questionnaire (DEBQ) for Assessment of Restrained, Emotional, and External Eating Behavior. International Journal of Eating Disorders, 5, 295-315. http://dx.doi.org/10.1002/1098-108X(198602)5:2<295::AID-EAT2260050209>3.0.CO;2-T

[33] Stice, E., Presnell, K., Lowe, M.R. and Burton, E. (2006) Validity of Dietary Restraint Scales: Reply to Van Strien et al. (2006). Psychologicaly Assessment, 18, 95-99. http://dx.doi.org/10.1037/1040-3590.18.1.95

[34] King, L.A. (2001) The Health Benefits of Writing about Life Goals. Personality and Social Psychology Bulletin, 27, 798-807. http://dx.doi.org/10.1177/0146167201277003

[35] Cohen, S., Kamarck, T. and Mermelstein, R. (1983) A Global Measure of Perceived Stress. Journal of Health and Social Behavior, 24, 385-396. http://dx.doi.org/10.2307/2136404

[36] Sandelowski, M. (2000) Whatever Happened to Qualitative Description? Research in Nursing \& Health, 23, 334-340. http://dx.doi.org/10.1002/1098-240X(200008)23:4<334::AID-NUR9>3.0.CO;2-G

[37] Sandelowski, M. (2010) What's in a Name? Qualitative Description Revisited. Research in Nursing \& Health, 33, 7784.

[38] Marcus, N. and Levin, G. (1977) Clinical Applications of Biofeedback: Implications for Psychiatry. Hospital \& Community Psychiatry, 28, 21-25.

[39] Ciampolini, M., Lovell-Smith, D., Bianchi, R., de Pont, B., Sifone, M., van Weeren, M., de Hahn, W., Borselli, L. and Pietrobelli, A. (2010) Sustained Self-Regulation of Energy Intake: Initial Hunger Improves Insulin Sensitivity. Journal of Nutrition and Metabolism, 2010, Article ID: 286952.

[40] Frankel, L.A., Hughes, S.O., O’Connor, T.M., Power, T.G., Fisher, J.O. and Hazen, N.L. (2012) Parental Influences on Children's Self-Regulation of Energy Intake: Insights from Developmental Literature on Emotion Regulation. Journal of Obesity, 2012, Article ID: 327259. http://dx.doi.org/10.1155/2012/327259

[41] Birch, L.L., McPhee, L., Sullivan, S. and Johnson, S. (1989) Conditioned Meal Initiation in Young Children. Appetite, 13, 105-113. http://dx.doi.org/10.1016/0195-6663(89)90108-6

[42] Bandura, A., Ross, D. and Ross, S.A. (1963) Vicarious Reinforcement and Imitative Learning. The Journal of Abnormal and Social Psychology, 67, 601-607. http://dx.doi.org/10.1037/h0045550 
Scientific Research Publishing (SCIRP) is one of the largest Open Access journal publishers. It is currently publishing more than 200 open access, online, peer-reviewed journals covering a wide range of academic disciplines. SCIRP serves the worldwide academic communities and contributes to the progress and application of science with its publication.

Other selected journals from SCIRP are listed as below. Submit your manuscript to us via either submit@scirp.org or Online Submission Portal.
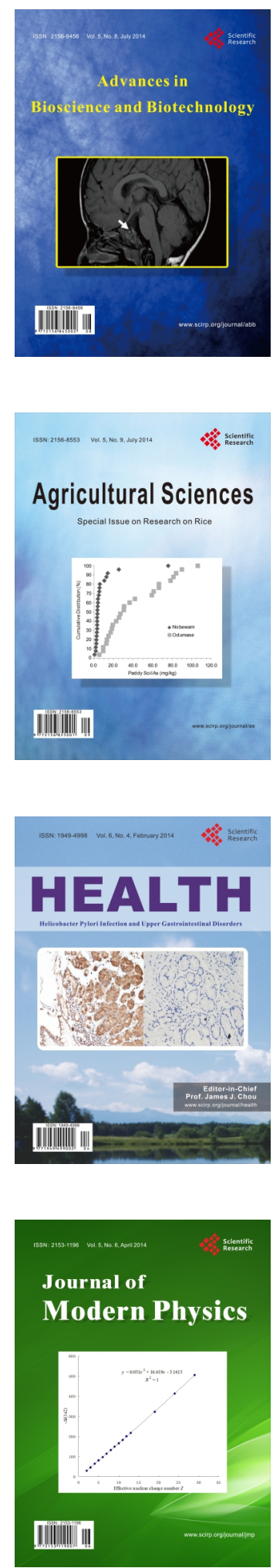
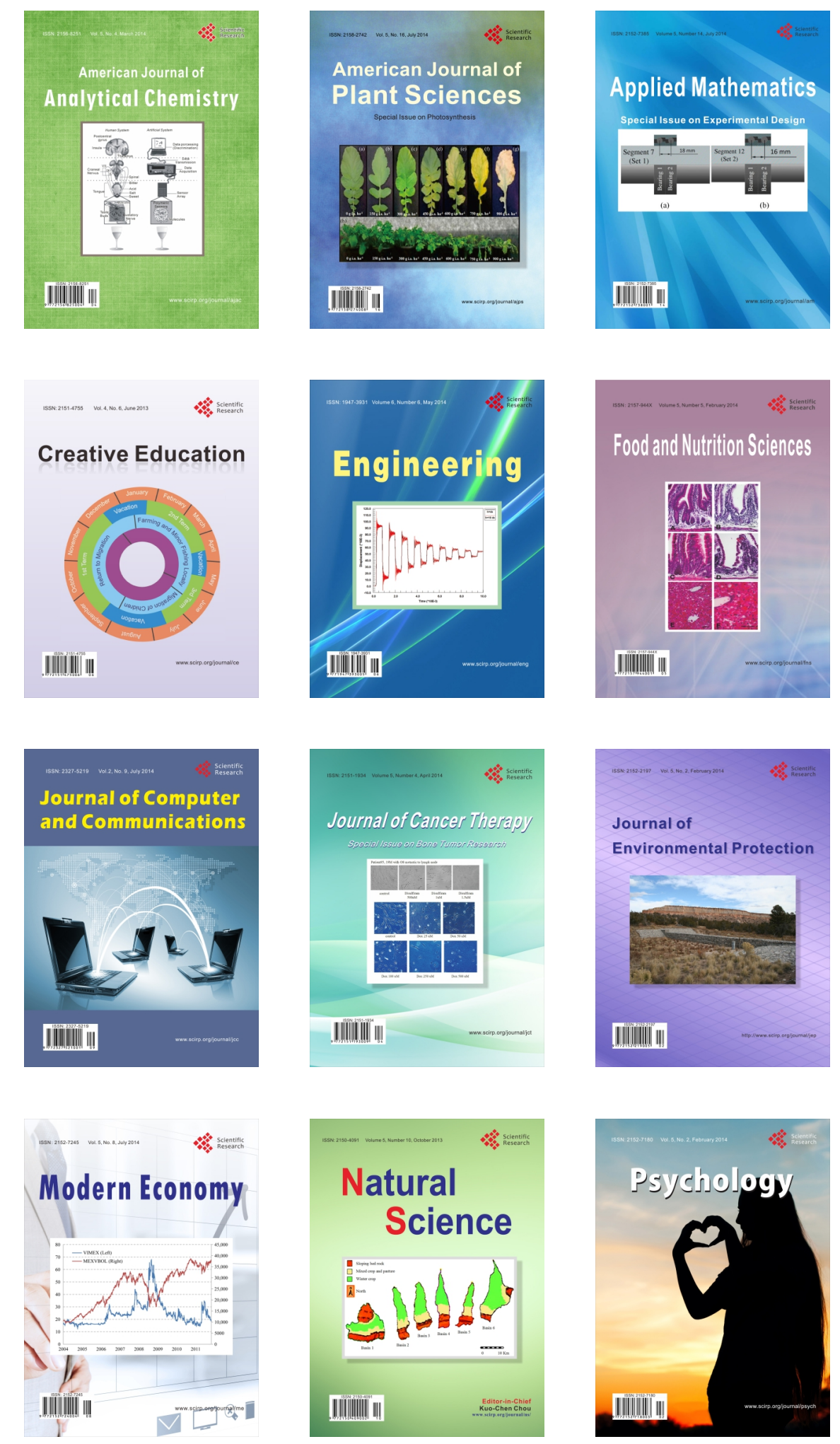